\title{
High Risk Posture on Motor-Manual Short Wood Logging System in Acacia mangium Plantation
}

\author{
Efi Yuliati Yovi", Widya Prajawati
}

\author{
Department of Forest Management, Faculty of Forestry, Bogor Agricultural University, Academic Ring Road, Campus IPB \\ Dramaga, PO Box 168, Bogor, Indonesia 16680
}

Received March 1, 2015/Accepted April 20, 2015

\begin{abstract}
Motor-manual logging has been considered as the most dominant logging system in Java Island, Indonesia. The system-which consist of felling, delimbing, bucking, hauling, and transporting activities- involves a combination of stress factors e.q. difficult work postures, generation offorce, and lifting techniques. In the other hand, combination of the stress factors is well associated with high risk of work-related musculoskeletal injuries (MSIs), including musculoskeletal disorders. This research aimed to assess difficult work posture on felling, delimbing, bucking, and manually short wood hauling by employing rapid entire body assessment (REBA) technique and muscular pain scoring based on the worker's perceive. It was revealed that felling and manual hauling were scored 4 in the REBA action level, indicated very high MSIs risk level, and categorized as "necessary now" for an injury risk preventive action. The workers' pain scoring indicated that low back (spine in general) disorders resulting in low back pain has been considered to be the one of the leading safety issues in the felling and manual hauling. Regardless to complex mechanism of how the personal risk and environmental factors associated with manual material handling injuries, job-related factors approach should be underlined in the MSIs prevention initiative in motor-manual logging.
\end{abstract}

Keywords: motor-manual logging, difficult work posture, REBA, MSIs, low back pain

*Correspondence author, email: eyyovi@ipb.ac.id, tel.: +62-251-8621244,fax.:+62-251-8621244

\section{Introduction}

It is undeniable that the motor-manual logging is physically strenuous work. Motor-manual logging has been considered as the most dominant logging system in both production forests and many community forests in Java Island, Indonesia. This system involves a combination of many stress factors, e.q. difficult work postures, generation of force, and lifting techniques, particularly in the manual hauling and loading. The stress factors influence energy expenditure (workload) in muscular work (Morrisey 1987) and part of the body that is imposed a lot by heavy muscular work is the spine (Jorgensen et al. 1985).

Affecting the maximal ability to produce force (Mital 1986), difficult work posture is considered as the common problem in manual handling activity such as the motormanual logging which is consisted of felling, delimbing, bucking, hauling, loading, and transporting activities. In addition, from physiological point of view, Yovi et al. (2005) stated that operating $15 \mathrm{~kg}$ chainsaw in felling activity consumes up to $78 \%$ of one's maximum work capacity. This implied that manual hauling and loading short wood with weight more than $30 \mathrm{~kg}$ each will definitely become a potential cause of more severe combination of difficult work posture and harder muscular work (i.e. forceful exertion, extreme posture, or prolonged difficult postures) which often end up in the higher risk of work-related musculoskeletal injuries (MSIs), including musculoskeletal disorders (MSDs).

MSDs which have been categorized as work-related occupational diseases (ILO 2010) are common work-related health problem and it have been taken seriously in many developed countries. A study by Leigh et al. (1999) revealed that the annual world incidence of MSDs represented $31 \%$ of all work-related diseases in 1994. This strongly indicated that MSDs are the most frequent work-related diseases, which further lower work productivity of employee with good work ability. MSDs also spend cost in significant amount as Piedrahita (2006) reported that MSDs cost as much as $0.2 \%$ of Columbia GDP in 2005.

The official data of MSDs cases in logging activity in Indonesia is hard to obtain and estimate. However it is believed that the work-related MSDs also cause serious health problems to the Indonesian logging workers, considering that logging is not only associated with very heavy workload activity, heavy material, and motor-manual system (Yovi et al. 2005), but it also closely associated with forceful exertion, excessive mechanical force concentration, awkward posture, and close body contact with vibration.

On the other side, most of forest operators involved in the motor-manual short wood logging system in Indonesia (1) have low education background, as well as (2) are 
outsourcing workers, (3) are paid under quantity done, (4) are consuming less sufficient nutrient, and (5) really depend on this activity as their main livelihood (Yovi et al. 2012). The combination of the characters makes the logging workers focus more on effort to get higher quantity done (means higher wage) than to work safely and healthily. As a result, workers have been trapped in a dangerous cycle of their work safety which could trigger negative impact on their health condition.

This way, safety and health protection of the workers should be focused on MSIs prevention through postural analysis. The control of postures is an important way of reducing the load on the vertebral discs, joints, and muscles (Chaffin \& Andersson 1991). There are many posture analysis systems such as a system developed by Priel (1974), OWAS (Karhu et al. 1977), and ARBAN (Holzmann 1982). All of the systems are aimed to identify and evaluate unsuitable work postures.

This research aimed to assess difficult work posture using rapid entire body assessment (REBA) technique. The activities assessed were activities involved in motor-manual logging which consisted of making felling and back cut, delimbing, bucking (all the three activities were carried out by the use of chainsaw), and manually short wood hauling. Results generated will be the basis for improvement of work posture, which will have further implications on the overall system work.

\section{Methods}

Activities studied were felling, delimbing, bucking, manual hauling. The data were taken at Acacia mangium plantations at Banten and West Java Province, Indonesia in June to July 2012. In these plantations, logging operation was carried out under motor-manual short wood system. The diameters of tree felled were 16-29 $\mathrm{cm}$ and $\log$ weights transported in hauling activities ranged between $18-70 \mathrm{~kg}$, with density ranged $0.46-0.53$. Weight of chainsaw used was $8 \mathrm{~kg}$ (gross weight).

The activities consist of several work postures, and some postures can be uncomfortable, extreme, or unstable. In this research, analyzed were work postures difficult/awkward/ high risk work postures which were the most frequently used and requiring muscle activity or strength in the highest level. The difficult work posture on each activity was determined through preliminary observation, the elected posture was then analyzed using REBA score sheet (Hignett \& McAtamney 2000).

REBA was employed to as this technique have been widely used in the postural analysis. REBA provides an assessment of the risk posture that can cause work-related MSDs disorders using a measurement technique that is easy and fast, so it can be used practically by ergonomic practitioners in the forestry sector. Hignett and Mc Atamney (2000) noted that REBA offers high quality of generality as well as sensitivity in work posture analysis.

There are 3 tables used in REBA. Table A (Table 1) represents a judgment on the part of the body (which is identified as Group A), consisting of the trunk, neck, and legs. Overall, there are 60 possible combinations of assessment in Group A. Table B (Table 2) represents a judgment on the part of the body (which is defined as Group B), consisting of the upper arm, lower arm, and wrist with 36 possible combinations. Factor load or force is added in the Group A, while the factor coupling is added for Group B. Then the A and B scores are combined in Table C (Table 3). Finally, after adding the activity score with Table $\mathrm{C}$ score, the final REBA score is obtained. This final REBA score is then converted into REBA action levels (Table 4).

A verification was carried out throught a survey collecting any complaints of musculoskeletal discomfort perceived by the respondents. In this analysis, chainsaw operators and manual hauling workers were required to score muscular pains they feel. The scoring was done in a scale of 1 (no pains at all) to 5 (extremely pains). Because the respondent characteristics were dominated by workers with low educational background resulted in limited literacy skills (Table 5), verification was carried out through structured interviews (with closed questions). Respondents of in-depth interview consisted of a group of chainsaw operators (including the helper) as many as 28 workers and hauling manual workers as many as 16 workers.

\section{Results and Discussion}

REBA analysis on the difficult work postures A total of 4 difficult work postures were identified through preliminary observation (Figure 1).

1 In felling activities, posture during making top cut (angled downward $45^{\circ}$ ) was considered as the most

Table 1 Group A and load

\begin{tabular}{|c|c|c|c|c|c|c|c|c|c|c|c|c|c|}
\hline \multicolumn{14}{|c|}{ Table A } \\
\hline \multirow[b]{3}{*}{ Trunk } & \multirow[b]{3}{*}{ Legs } & \multicolumn{12}{|c|}{ Neck } \\
\hline & & \multicolumn{4}{|c|}{1} & \multicolumn{4}{|c|}{2} & \multicolumn{4}{|c|}{3} \\
\hline & & 1 & 2 & 3 & 4 & 1 & 2 & 3 & 4 & 1 & 2 & 3 & 4 \\
\hline 1 & & 1 & 2 & 3 & 4 & 1 & 2 & 3 & 4 & 3 & 3 & 5 & 6 \\
\hline 2 & & 2 & 3 & 4 & 5 & 3 & 4 & 5 & 6 & 4 & 5 & 6 & 7 \\
\hline 3 & & 2 & 4 & 5 & 6 & 4 & 5 & 6 & 7 & 5 & 6 & 7 & 8 \\
\hline 4 & & 3 & 5 & 6 & 7 & 5 & 6 & 7 & 8 & 6 & 7 & 8 & 9 \\
\hline 5 & & 4 & 6 & 7 & 8 & 6 & 7 & 8 & 9 & 7 & 8 & 9 & 9 \\
\hline \multicolumn{14}{|c|}{ Load/force } \\
\hline $\begin{array}{r}0 \\
<5\end{array}$ & & & $\begin{array}{r}1 \\
5-10\end{array}$ & & & $\begin{array}{c}2 \\
>10 \mathrm{~kg}\end{array}$ & & & $\begin{array}{c}+1 \\
\text { Shock }\end{array}$ & $i d b$ & of & & \\
\hline
\end{tabular}


Table 2 Group B and coupling

\begin{tabular}{|c|c|c|c|c|c|c|c|}
\hline \multicolumn{8}{|l|}{ Table B } \\
\hline & \multicolumn{7}{|c|}{ Lower arm } \\
\hline \multirow[b]{2}{*}{ Upper arm } & \multirow[b]{2}{*}{ Wrist } & \multicolumn{3}{|c|}{1} & \multicolumn{3}{|c|}{2} \\
\hline & & 1 & 2 & 3 & 1 & 2 & 3 \\
\hline 1 & & 1 & 2 & 3 & 1 & 2 & 3 \\
\hline 2 & & 1 & 2 & 3 & 2 & 3 & 4 \\
\hline 3 & & 3 & 4 & 5 & 4 & 5 & 5 \\
\hline 4 & & 4 & 5 & 5 & 5 & 6 & 7 \\
\hline 5 & & 6 & 7 & 8 & 7 & 8 & 8 \\
\hline 6 & & 7 & 8 & 8 & 8 & 9 & 9 \\
\hline \multicolumn{8}{|l|}{ Coupling } \\
\hline \multirow{2}{*}{\multicolumn{2}{|c|}{$\begin{array}{l}0 \text {-good } \\
\text { Well -fitting handle and a } \\
\text { mid -range, power grip }\end{array}$}} & \multirow{2}{*}{\multicolumn{2}{|c|}{$\begin{array}{l}\text { 1-fair } \\
\text { Hand hold acceptable but not } \\
\text { ideal or coupling is acceptable } \\
\text { via another part of the body }\end{array}$}} & \multirow{2}{*}{\multicolumn{2}{|c|}{$\begin{array}{l}\text { 2-poor } \\
\text { Hand hold not acceptable } \\
\text { although possible }\end{array}$}} & \multicolumn{2}{|c|}{ 3-unacceptable } \\
\hline & & & & & & $\begin{array}{l}\text { Awk } \\
\text { hanc } \\
\text { unac } \\
\text { part }\end{array}$ & $\begin{array}{l}\text { fe grip, no } \\
\mathrm{ng} \text { is } \\
\text { sing othe } \\
\text { ly }\end{array}$ \\
\hline
\end{tabular}

Tabel 3 Table $\mathrm{C}$ and activity

\begin{tabular}{|c|c|c|c|c|c|c|c|c|c|c|c|}
\hline \multirow[b]{3}{*}{$\mathrm{S}$} & \multirow[b]{3}{*}{1} & \multirow[b]{2}{*}{1} & \multirow[b]{2}{*}{2} & \multicolumn{8}{|c|}{ Score B } \\
\hline & & & & 3 & 4 & 5 & 6 & 7 & 8 & 9 & 10 \\
\hline & & 1 & 1 & 1 & 2 & 3 & 3 & 4 & 5 & 6 & 7 \\
\hline $\mathrm{c}$ & 2 & 1 & 2 & 2 & 3 & 4 & 4 & 5 & 6 & 6 & 7 \\
\hline o & 3 & 2 & 3 & 3 & 3 & 4 & 5 & 6 & 7 & 7 & 8 \\
\hline $\mathrm{r}$ & 4 & 3 & 4 & 4 & 4 & 5 & 6 & 7 & 8 & 8 & 9 \\
\hline \multirow[t]{2}{*}{ e } & 5 & 4 & 4 & 4 & 5 & 6 & 7 & 8 & 8 & 9 & 9 \\
\hline & 6 & 6 & 6 & 6 & 7 & 8 & 8 & 9 & 9 & 10 & 10 \\
\hline \multirow[t]{6}{*}{ A } & 7 & 7 & 7 & 7 & 8 & 9 & 9 & 9 & 10 & 10 & 11 \\
\hline & 8 & 8 & 8 & 8 & 9 & 10 & 10 & 10 & 10 & 10 & 11 \\
\hline & 9 & 9 & 9 & 9 & 10 & 10 & 10 & 11 & 11 & 11 & 12 \\
\hline & 10 & 10 & 10 & 10 & 11 & 11 & 11 & 11 & 12 & 12 & 12 \\
\hline & 11 & 11 & 11 & 11 & 11 & 12 & 12 & 12 & 12 & 12 & 12 \\
\hline & 12 & 12 & 12 & 12 & 12 & 12 & 12 & 12 & 12 & 12 & 12 \\
\hline \multicolumn{12}{|c|}{ Activity score } \\
\hline \multicolumn{12}{|c|}{$\begin{array}{l}+1=1 \text { or more body parts are static, e.g. held for longer than } 1 \mathrm{~min} \\
+1=\text { Repeated small range actions, e.g. repeated more than } 4 \text { times per minute (not including walking) } \\
+1=\text { Action causes rapid large changes in postures or an unstable base }\end{array}$} \\
\hline \multicolumn{12}{|c|}{ e 4 REBA action levels } \\
\hline & & \multicolumn{2}{|c|}{ Action level } & \multicolumn{2}{|c|}{ REBA score } & \multicolumn{2}{|c|}{ Risk level } & \multicolumn{4}{|c|}{ Action (including further assessment) } \\
\hline & & \multicolumn{2}{|c|}{0} & \multicolumn{2}{|c|}{1} & \multicolumn{2}{|c|}{ Negligible } & \multicolumn{4}{|c|}{ None necessary } \\
\hline & & \multicolumn{2}{|c|}{1} & \multicolumn{2}{|c|}{$2-3$} & \multicolumn{3}{|c|}{ Low } & \multicolumn{3}{|c|}{ May be necessary } \\
\hline & & \multicolumn{2}{|c|}{2} & \multicolumn{2}{|c|}{$4-7$} & \multicolumn{3}{|c|}{ Medium } & \multicolumn{3}{|c|}{ Necessary } \\
\hline & & \multicolumn{2}{|c|}{3} & \multicolumn{2}{|c|}{$8-10$} & \multicolumn{3}{|c|}{ High } & \multicolumn{3}{|c|}{ Necessary soon } \\
\hline & & \multicolumn{2}{|c|}{4} & & & & & & Necessar & & \\
\hline
\end{tabular}

Table 5 REBA score and muscular pain complain on each difficult work posture

\begin{tabular}{lllccc}
\hline Activity & Difficult work posture & Body part where the pain is felt & \multicolumn{2}{c}{ REBA score } \\
\cline { 3 - 5 } & & & $\begin{array}{c}\text { Group } \\
\text { A }\end{array}$ & $\begin{array}{c}\text { Group } \\
\text { B }\end{array}$ & Score \\
\hline Felling & Making top cut & Low back, left upper arm, left & 8 & 6 & 12 \\
Delimbing & $\begin{array}{l}\text { Slightly bent and static standing when arm, upper back } \\
\text { sawing twigs/branches }\end{array}$ & $*$ & 3 & 5 & 5 \\
Bucking & Trimming/bucking hanging trunk & $\begin{array}{l}* \\
\text { right lower arm, neck }\end{array}$ & 6 & 6 & 9 \\
Hauling & Lifting the log into the right shoulders & $\begin{array}{l}\text { Low back, right shoulder, } \\
\text { upper back, right up per arm, } \\
\text { right lower arm, neck }\end{array}$ & 10 & 9 & 14 \\
\hline
\end{tabular}


difficult work posture. In this posture, chainsaw operators had to bend or twist their back and squat while operate a chainsaw (Figure 1a).

2 The morphology of Acacia mangium of 6 year old lead delimbing without involving a large tree limb or hardwood fibers. Work elements in delimbing activities consisted of (1) moving (walking by carrying chainsaw) to the next branch and (2) sawing while standing still. Considering, the dominant work element was sawing branches/twigs, so that slightly bent and static standing when sawing twigs/branches was chosen as the difficult work posture during delimbing activity (Figure 1b).

3 The selected difficult work posture at bucking activities was vertical cutting a hanging trunk section (supported at one end only) (Figure 1c). All chainsaw operators claimed this work posture is the most difficult among the other work postures during bucking.

4 Manual hauling consisted of work elements of lifting logs in the right shoulder, bearing logs, and laying logs into a pile. From the 3 work postures, lifting logs in the right shoulder was considered as the most difficult work posture (Figure 1d). The work was an asymmetric vertical lifting with weight load of up to $70 \mathrm{~kg}$.

Making top cut Field observations indicated that a chainsaw operator can cut down as many as 30-40 trees per day. Because of the tree diameter were relatively small, the effective time of making face (both top and bottom cut) and back cut was around 2 minutes, depending on the diameter of the trees felled. In this posture, worker's trunk flexed more than $60^{\circ}$ (score 4) and side flexed (score 1), so that, the REBA score at this position was 5 . The extended neck got a score of 2. Legs got a score of 2 because the legs beard the worker with flexion of $30-60^{\circ}$. Based on diagram of Group A, REBA score for this group was 7 . In addition, in this activities the worker operated an $8 \mathrm{~kg}$ chainsaw so that there was a score addition $(+1)$ in the final calculation. Therefore, the final REBA score for Group A was 8.

Calculations for Group B were performed only on the left side of the body because when operating chainsaws, the right hand was more widely used to control the chainsaw, and the chainsaw weight was more dominantly endured by left hand. Left upper arm was flexed between $45-90^{\circ}$, so it got a score of 3. However, the score of 1 was added as it was abducted and no gravity assisted. This made for left upper arm the score was 4. Lower arm was flexed between $0-60^{\circ}$, therefore the REBA score was 2, while the wrist was flexed less than $15^{\circ}$ with a twist, scored as 1 . Therefore, the score according to Group B diagram was 5. Because of the acceptable but not ideal hand hold, the coupling score $(+1)$ was added to get the total score of Group B to be 6 .

By combining the scores of Group A (8) and Group B (6), the score in Table $\mathrm{C}$ was 10 . Activity score 2 was added as there has been a static body part $(+1)$ and the rapid action has caused large changes in postures $(+1)$. Therefore, the total REBA score for making face cut was 12 , indicating a very high risk of musculoskeletal injury. An assessment to the task to reduce the risk level was categorized as "necessary now" (Table 4).

Postural analysis on delimbing Delimbing work expended for more than 3 minutes per tree. In this study, one operators performed both felling and delimbing using the same chainsaw. Delimbing work was done immediately after the tree was felled. The difficult posture in this activity made the worker's trunk flexed between 20-60 (score 3) and relatively no side flexed, so that REBA score at this position was 3 . The neck was flexed less than $20^{\circ}$ so it scored 1 . Posture of legs was scored 1 because the legs were both weight bearing. This way, the table of Group A showed the score 2 . The same with the activity of making top cut, in this activity, worker operated $8 \mathrm{~kg}$ chainsaw so that a score of 1 was added to the final calculation of Group A. The final score for Group A was 3.

Similar to the activity of making top cut, the calculation of Group B was performed only on the left side of the body because the left body experiences greater load than the right side. Left upper arm flexed between $20-45^{\circ}$ got a score of 2 , and since it was abducted $(+1)$ and no gravity assisted, the total score for the upper right arm was 3 . Lower arm was flexed less than $60^{\circ}$, therefore the REBA score was 2 . Since the wrist was flexed among $0-15^{\circ}$ and twisted, this posture was scored as 1 . Therefore, the REBA score for Group B was 4 and the coupling score (1) was added to get the total score of Group B to be 5 .

By combining the scores of Group A (3) and Group B (5), score in Table $\mathrm{C}$ was 4 . Activity score $(+1)$ then was added as there has been a static body parts when the workers

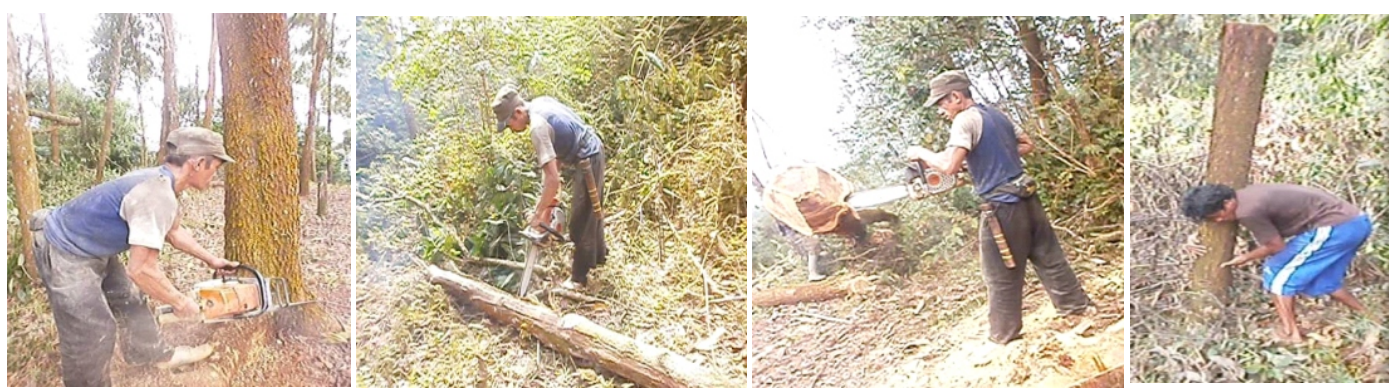

Figure 1 The difficult work postures at activities of (a) felling, (b) delimbing, (c) bucking, and (d) hauling. 
hold this posture for more than 1 minute. This made the total REBA score was 5, indicating a medium risk of musculoskeletal injury. An assessment to the task to reduce the risk level was categorized as "necessary" in the REBA action level (Table 4)

Postural analysis on bucking Sawing hanging tree trunk lead to an extended trunk between $0-20^{\circ}$ so it got score of 2 , however, score 1 was added since there was one side trunk flexed. Therefore, the score for the trunk was 3 . To maintain a range of views, workers tended to lowering their heads so that the necks were flexed more than $20^{\circ}$ to get score of 2 . The position of the legs on this work posture was scored 1 because during this posture, legs were both weight bearing and flexed below $30^{\circ}$. Therefore, the total score of Table A for this posture was 4 . Since the worker operated $8 \mathrm{~kg}$ chainsaw, score 1 was added in the final calculation of the Group A score, so that the end result of Group A was 5.

The total result in the calculation of Group B to the left side of the body was 6 . This was due to the upper left arm flexed between $45-90^{\circ}$ which lead to score of 3 . Score of +1 was added as it is abducted and no gravity assisted. Therefore, score for the upper arm was 4. The lower arm was flexed between $0-60^{\circ}$ caused a score of 2 . Left wrist got a score of 1 because of flexion between $0-15^{\circ}$ and twisted. Table B shows the REBA score for this work posture was 5 . Score of 1 was added for the coupling as a hand hold was acceptable but not ideal, so the total score of Group B for this activity was 6 .

By combining the scores of Group A(6) and Group B score (6), the score in Table $C$ was 8 . Activity score (1) was added as there has been a static body part. Therefore, the total REBA score was 9 , indicating a high risk of musculoskeletal injury. Assessment to the task to reduce the risk level was categorized as "necessary soon" in the REBA action level (Table 4).

Manual hauling The most difficult work posture for manual hauling happenned when workers perform lifting (Figure $1 \mathrm{~d}$ ), regardless to the fact that the time required for this posture was less than 10 second (depended on the log dimension). However, considering the fact that the heavy logs were carried variously between $18-70 \mathrm{~kg}$ meant the value of lifting index (LI) was up to 3 , this activity should get serious concern as any handling tasks with LI $>1$ may result in an increased risk of lower back injury to workers. In addition, the risk of injury becomes higher as the average bear of worker was 20-30 logs per day with lifting distance ranging between 5-40 m. Workers perform this posture oftenly since there was no any assist devices available.

This manual lifting caused trunk flexed over $60^{\circ}$ (score 4 ) and side flexion was significantly exist (score 1), so that the REBA score for trunk in this position reached the highest value of 5 . Neck was flexed more than $20^{\circ}$ so it got a score of 2 . Score of 3 was added for legs as legs were both weight bearing and flexed more than $60^{\circ}$. Therefore, the score for Group A was 8 . Further, in relating to load/force, score of 1 was added for the load weight was over $10 \mathrm{~kg}$, and another score of +1 was added since the lifting movement caused a rapid build up of force. Finally, the score of Group A was 10.

Right upper arm flexed between $45-90^{\circ}$ and it was scored 3 , and since it was abducted and no gravity assisted, the total score for the upper right arm was 4 . Lower arm was flexed over $100^{\circ}$, therefore the score was 2 . To hold the log strongly, wrist was extended over $15^{\circ}$ and twisted, lead to the score of 2. Therefore, the REBA score for Group B was 6 . Since this work involves awkward posture and unsafe grip, the coupling score of 3 was added. Finally, the total score for the Group B was 9.

By combining the scores of Group A (10) and Group B (9), the score in Table $\mathrm{C}$ was determined as 12. Further, score of activity $(+2)$ was added as the action caused large rapid changes in posture and shoulders performed static movement along the lifting. This way, the total REBA score was 14, indicating a very high risk of musculoskeletal injury. An assessment to the task to reduce the risk level was categorized as "necessary now" in the REBA action level.

Muscular pain complains In this stage, the respondent were divided into 2 groups following the results of REBA analysis: (1) chainsaw operators who imposed with difficult work posture during making top cut and (2) hauling workers who imposed with difficult posture during manual lifting. It was factual that when work, the tasks of chainsaw operators were not only limited to felling, but also delimbing and bucking, as well. Therefore, it was difficult to separate the specific complaints on each activity. This study therefore used the assumption that the complaint expressed by chainsaw operators was caused by the hardest work posture among work postures in the 3 activities, i.e. making the top cut during felling.

The results showed that there were differences of distribution and the level of muscular pains felt by both respondent groups (Figure 2). Chainsaw operators mentioned that the muscular pain felt, from the most severe to lightest, was in the low back, left upper arm, right lower arm, and upper back, respectively. Manual hauling workers also mentioned their great pain complaints in low back besides right shoulder, upper back, right upper arm, right lower arm, and neck.

The low back pain complained by the operators occured when they have to bent (in some cases they have to squat down, Takimoto et al. 2005) while operating a chainsaw of 8 $\mathrm{kg}$ or often more because the cutting point is located very close to the forest floor (sometimes only $15 \mathrm{~cm}$ high). Chaffin and Anderson (1991) mentioned that moment at the hip joint can become large when a load is lifted, and since lumbar spine is anatomically close to the hip joint, this effect also occurs in the joints of the lumbar spine. This is a potential health problem as these operators are not only carrying or lifting up the chainsaw, but also doing maneuver and in the same time, controlling the chainsaw. Similar with the chainsaw operators, manual hauling workers claimed that the pain (scored 5 of 1-5 scale) was mostly experienced in the low back. This is very understandable because they did not only deal with $8 \mathrm{~kg}$ chainsaw, but they had to lift $17-70 \mathrm{~kg}$ logs, alone, in 20-30 times of repetitions per day. The fact that both job types demand heavy muscular work that very much imposes the spine seems to be the strong reason behind their complains in low and upper back (Jorgensen et al. 1985).

It should be underlined that both groups of workers stated 
that the pain in their low back only relief after they take days off, while the pain in other parts of the body healed overnight. However, there was clear evidence in the form of hardening of the muscles on the right shoulder of manual hauling worker (Figure 3) which at least indicated that the muscular injury on the body was not recovered in just one night. This situation should be seen as an obvious indication that the workers are facing the MSIs problems.

Overall, muscular pain complaints of manual hauling workers were relatively more severe than that of chainsaw operators. These complaints are in the line with the results of REBA analysis (Table 5). The posture during felling and back cutting imposed operators with high muscular load in the trunk, neck, and legs and was scored 8 for Group A. However, the load was more severe in lifting because it was scored 10 . The Group B body part for felling activity was scored 6, while that for manual hauling was scored 9. The analysis then ended up with very high level of muscular risk far above the risk for delimbing and bucking (Table 6).

Work improvement The finding above clearly indicated that combination of difficult posture (emerged by manual handling) and heavy work load in motor-manual logging system potentially makes the workers end up with MSIs especially in low back muscle due to overexertion. The workers' pain scoring shows that low back disorders resulting in low back pain should be considered to be the one of the leading safety issues in the motor-manual logging system,

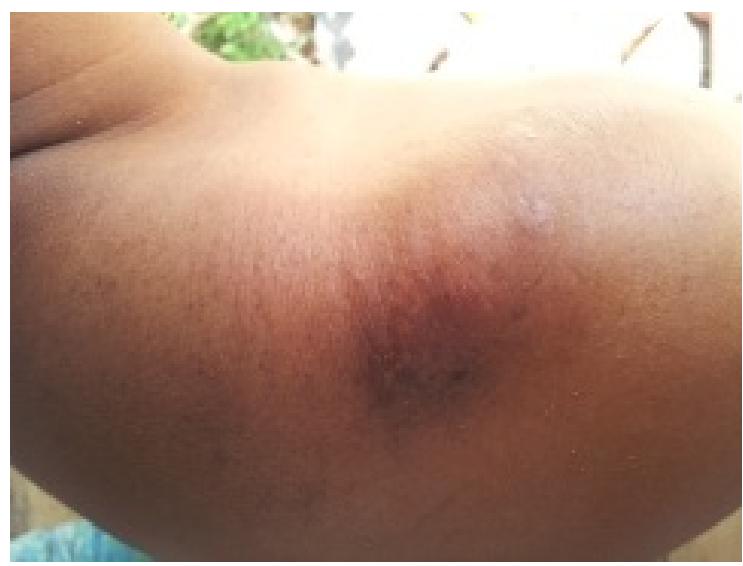

Figure 3 Hardening on the shoulder accompanied by pain due to excessive lifting.

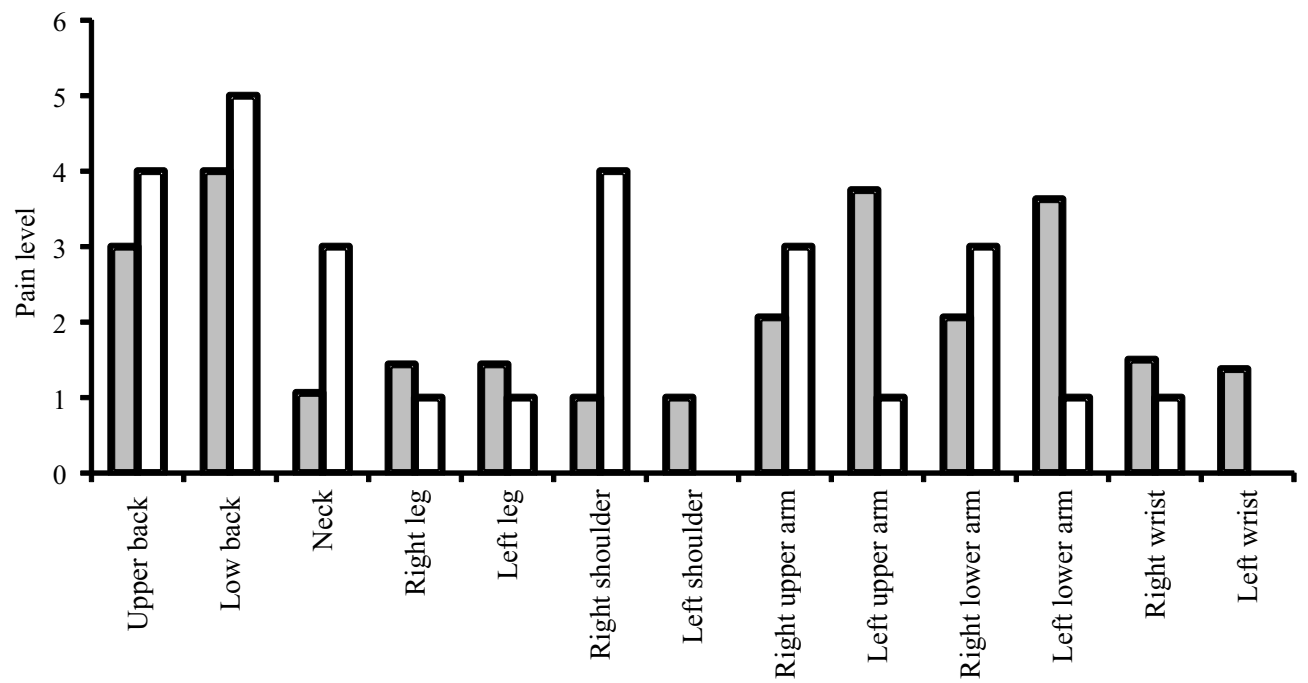

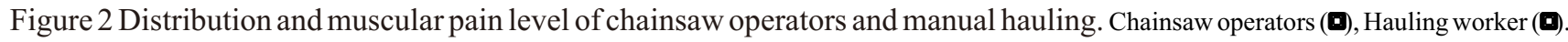

Table 6 REBA action level of motor-manual short wood logging activities.

\begin{tabular}{lccll}
\hline Activity & Action level & Score REBA & Risk level & Action \\
\hline Felling & 4 & 12 & Very high & Necessary now \\
Delimbing & 3 & 5 & Medium & Necessary \\
Bucking & 3 & 9 & High & Necessary soon \\
Hauling & 4 & 14 & Very high & Necessary now \\
\hline
\end{tabular}


especially in the manual felling and hauling.

Waters and Putz-Anderson (1996) noted that there are 3 factors associated with manual handling injuries. They are personal risk factors, environmental factors, and job-related factors. In case of personal risk factors, they mentioned that the personal factors potentially modify the body respond to the exertions emerge during manual handling work. The environmental factor influencing the possibility of injuries in this study is only humidity, and it should be noted that this is a given factor which means that there is no way to modify this factor by any chance. Therefore, the MSIs prevention initiative should deal with the third factor namely job-related factors. However, it should be noted that there is a complex relationship among the factors. These factors cannot act independently so they must be interactive or multiplicative.

The items included in the job-related factors that relate to the work posture improvement for this study are location of the relative load to the body, the moved object distance, and the frequency and duration of handling. The other related factors are bending and twisting work posture, and weight of the object or force required to over the object. These factors are in line with the results of many studies which are cited by the NIOSH Guide, 1981, revealing that musculoskeletal injury rate increases significantly, when (a) it lifts heavy objects, (b) the object is in huge/big dimension, (c) the object is lifted from the floor, and (d) the lifting position is performed frequently (Chaffin \& Anderson 1991).

The local muscular fatigue occurs due to heavy load and the muscle will need a longer period of recovery to their previous state (Waters \& Putz-Anderson (1996). Fatigue will develop if heavy effort is sustained for a long duration. A study on pine resin harvesting period in which includes walking, asymmetric lifting, and carrying indicates the similar action patterns (Takimoto et al. 2005). The lighter the load is the sooner the heart rate to reach its normal rate. From the physiological point of view, avoiding the accumulation of physical fatigue through (a) the force exertion in shorter duration and (b) the decrease of the frequent muscle effort is good approach in prevention of musculoskeletal injury.

From psychophysical point of view, subjective judgment or perception to the physical stress is necessary in assessing physical stress during work (Snook \& Ciriello 1991). Some methods such as rating of perceived exertion (RPE) and body part discomfort (BPD) have been used as instant confirmation. However, it should be noted that in subjective perception, an "acceptable" limits may different from the "safe" limit (Waters \& Putz-Anderson (1996).

In the implementation stage, efforts should be made to avoid exposure to MSIs which can be approached through a combination of 3 aspects: (a) personal work habits, (b) improvement of work methods, and (c) improvement of the work equipment (Väyrynen \& Könönen 1991). In the context of personal work habits, improvements for chainsaw operators consist of keeping a firm grip during sawing, keeping the chainsaw close to the operator's body, and keeping the body in a stable position during sawing. In the context of work methods, improvement may perform the cutting in the shortest period by applying proper cutting technique and avoiding frequent cutting with insufficient resting between felling. While using lighter chainsaws and well maintained, and using sharp sawchain only are attempts to do in the context of improvement of the work equipment.

The recommended personal work-related habits improvement for manual hauling work consisted of strictly avoid lifting over $21 \mathrm{~kg}$ of logs alone (which is approximately equal to $2 \mathrm{~m}$ length with around $17 \mathrm{~cm}$ in diameter). This 21 $\mathrm{kg}$ of weight were estimated based on Snook and Ciriello (1991) using assumption that widht (the dimension away from body) was $34 \mathrm{~cm}$, distance (vertical lift) was $51 \mathrm{~cm}$, percent pertain to industrial population was $50 \%$, and considered the absence of handles and extended reach in knee to shoulder. If the work condition makes it difficult for the usage of such assist device, carried out lifting (and the entire process of manual hauling) in a group should be considered as an alternative of lifting technique (Takimoto \& Yovi 2003). Avoiding long distance of hauling, increasing frequency of resting pause between hauling base of individual need (Takimoto et al. 2004), and avoiding frequent lifting can be categorized as a recommendation related to aspects of work methods. However, it should be noted that there is no optimal lifting technique which is generally suitable for all individuals in the same work tasks.

Finally, it should be underlined that any practical and theoretical recommendations will never solve the actual problems as long as there is no adequate knowledge of OSH. The knowledge will encourage changes in not only attitude, but also behavior as Channing (2003) mentioned that the possession of adequate $\mathrm{OSH}$ knowledge will positively influenced the safe behavior of workers.

\section{Conclusion}

The REBA analysis showed that work postures in felling, bucking and manual hauling in motor-manual logging system have high/very high risk level of MSDs. Subjective muscular pain complaint analysis indicated the same result as most of the workers involved in the activities complained about body part muscular pain, especially Iow back pain, that only relief after take days off. This implied that the MSIs is one of leading safety issues in the logging system that may reduce the quality of life of the forestry workers. Regardless to complex mechanism of how risk factors associated with manual material handling, the MSIs prevention initiative in motor-manual logging should be directed through jobrelated factors approach. In the implementation stage, the approached can be designed through a combination of personal work habits, improvement of work methods, and improvement of the work equipment.

\section{References}

Chaffin DB, Anderson GBJ. 1991. Occupational Biomechanics. Second Edition. New York: John Wiley \& Sons, Inc.

Channing JE. Risk management and behavior modification. In: Safety at Work. Ridley J, Channing J, editors. Six Edition. 2003. Great Britain: Butterworth Heinemann.

Hignett S, McAntamney L. 2000. Technical note rapid entire body assessment (REBA). Applied Ergonomics 31 (201-205). www.safetynet.co.kr//2008227134434 123. 
[15 May 2012].

Holzmann P. 1982. ARBAN-A new method for analysis of ergonomic efforts. Applied Ergonomics 13:82-86. http://dx.doi.org/10.1016/0003-6870(82)90183-1.

[ILO] International Labour Organization. 2010. List of occupational diseases (revised 2010). Occupational Safety and Health Series No. 74.

Jorgensen K, Andersen B, Horst D, Jensen S, Nielsen A. 1985. The load on the back in different handling operations. Ergonomics 28(1):183-196. http://dx.doi. org/10.1080/00140138508963127.

Karhu O, Kansi P, Kuorinka I. 1977. Correcting working postures in industry. Applied Ergonomics 18:199-201. http://dx.doi.org/10.1016/0003-6870(77)90164-8.

Leigh J, Macaskill P, Kuosma E, Mandryk J. 1999. Global burden of diseases and injuries due to occupational factors. Epidemiology 10(5):626-631. http://dx.doi.org/ 10.1097/00001648-199909000-00032.

Mital A. 1986. Effect of body posture and common hand tools on peak torque exertion capabilities. Applied Ergonomics 17(2):87-96. http://dx.doi.org/10.1016/ 0003-6870(86)90245-0.

Morrisey SJ. 1987. Influences of task posture on physiological task responses. International Journal of Industrial Ergonomics 1(3):209-217. http://dx.doi.org/ 10.1016/0169-8141(87)90015-1.

Piedrahita H. 2006. Costs of work-related musculoskeketal disorders MSDs) in developing countries: Columbia case. International Journal of Occupational Safety and Ergonomics 12(4): 379-386.

Priel VC. 1974. A numerical definition of posture. Human
Factors 16:576-584.

Snook SH, Ciriello VM. 1991. The design of manual handling tasks: revised tables of maximum acceptable weights and forces. Ergonomics 34:1197-1213. http://dx.doi.org/10.1080/00140139108964855.

Takimoto Y, Yovi EY. 2003. Workload and work efficiency of manual log transportation in Java: factors influencing transporting. The Japan Forest Engineering Society 18(2):75-84.

Takimoto Y, Yovi EY, Matsubara C. 2004. Workload during walking motion in pine resin harvesting in Java's plantation forest. The Japan Forest Engineering Society 19(2): 107-118.

Väyrynen S, Könönen U. 1991. Short and long-term effects of a training programme on work postures in rehabilitees: a pilot study of loggers suffering from back troubles. International Journal of Industrial Ergonomics 7:103-109. http://dx.doi.org/10.1016/01698141(91)90041-J.

Waters TR, Putz-Anderson V. 1996. Manual Material Handling in Occupational Ergonomics; Theory and Applications. Bhattacharya A, McGlothlin JD, editors. New York: Marcel Dekker, Inc.

Yovi EY, Takimoto Y, Ichihara K, Matsubara C. 2005. A study of workload and work efficiency in timber harvesting by using chainsaw in pine plantation forest in Java Island: clear cutting operation. Applied Forest Science 14(1):17-26.

Yovi EY, Gandaseca S, Adiputra IN. 2012. Worker's competency and perception toward safety and health on forest harvesting operation in Indonesian long rotation plantation forest. Jurnal Manajemen Hutan Tropika 18(3):198-205. http://dx.doi.org/10.7226/jtfm.18.3. 198. 